\title{
DENUDAÇÃO QUÍMICA E IMPLICAÇÕES NA COMPOSIÇÃO DAS ÁGUAS SUPERFICIAIS DA BACIA DO RIO JAÚ (SP)
}

\section{GEOCHEMICAL DENUDATION AND IMPLICATIONS IN COMPOSITION OF SURFACE WATERS FROM JAÚ RIVER BASIN (SP)}

Diego de Souza Sardinha
Instituto de Ciência e Tecnologia - Universidade Federal de Alfenas. Campus Avançado de Poços de Caldas - BR 267
Km 533, Rodovia José Aurélio Vilela, nº 11.999, Cidade Universitária-CEP: 37715-400-Poços de Caldas (MG). -
e-mail: diegosardinha@yahoo.com.br

Daniel Marcos Bonotto

Departamento de Petrologia e Metalogenia - Instituto de Geociências e Ciências Exatas - Universidade Estadual Paulista Júlio de Mesquita Filho. Av. 24-A, 1515, C. P. 178, Bela Vista. Rio Claro (SP) - CEP 13506-900. -

e-mail:dbonotto@rc.unesp.br

Letícia Hirata Godoy

Programa de Pós-graduação em Geologia Regional - Instituto de Geociências e Ciências Exatas - Universidade Estadual Paulista Júlio de Mesquita Filho. Av. 24-A, 1515, C. P. 178, Bela Vista. Rio Claro (SP) - CEP 13506-900. -

e-mail: leticiahirata@gmail.com

Fabiano Tomazini da Conceição

Departamento de Planejamento Territorial e Geoprocessamento - Instituto de Geociências e Ciências Exatas Universidade Estadual Paulista Júlio de Mesquita Filho. Av. 24-A, 1515, C. P. 178, Bela Vista. Rio Claro (SP) - CEP

13506-900.e-mail:ftomazini@rc.unesp.br

Maria Margarita Torres Moreno

Departamento de Petrologia e Metalogenia - Instituto de Geociências e Ciências Exatas - Universidade Estadual Paulista Júlio de Mesquita Filho. Av. 24-A, 1515, C. P. 178, Bela Vista. Rio Claro (SP) - CEP 13506-900.

e-mail:mmoreno@rc.unesp.br

\section{Informações sobre o Artigo}

Data de Recebimento:

25/03/2012

Data de Aprovação:

14/03/2013

\section{Palavras-chave:}

Bacia hidrográfica; química das águas superficiais; interação água-rocha.

\section{Keywords:}

Watershed; surface waters chemistry; water-rock interaction.

\begin{abstract}
Resumo
Este trabalho avaliou a denudação química e suas implicações na composição das águas superficiais da bacia do Rio Jaú, seis pontos de amostragem foram estabelecidos e realizaram-se seis amostragens (14/08/2009, 17/09/2009, 17/10/2009, 20/11/2009, 23/12/2009 e 12/01/2010), envolvendo os períodos seco e chuvoso. As análises foram executadas para vazão, temperatura, $\mathrm{pH}$, condutividade elétrica, cálcio, magnésio, sódio, potássio, sílica, cloreto, sulfato, fosfato e nitrato. Os resultados indicam que os parâmetros cálcio, magnésio e nitrato possuem um comportamento semelhante, ou seja, aumentam de montante (P1 e P3, sedimentos da Formação Itaqueri e a unidade de relevo Colinas Médias) para jusante (P2 e P4, Morrotes Alongados e Espigões associados às rochas ígneas da Formação Serra Geral). No Rio Jaú (P5 e P6) que também drena os basaltos da Formação Serra Geral, com exceção de $\mathrm{Ca}^{2+}, \mathrm{Mg}^{2+}$ e $\mathrm{Cl}^{-}$todos os outros parâmetros analisados possuem uma concentração maior no ponto $\mathrm{P} 6$, próximo à foz com o Rio Tietê. No entanto, a soma total de cátions e ânions ( $\left.\mathrm{t} / \mathrm{km}^{2} / \mathrm{ano}\right)$ é maior no ponto P5,

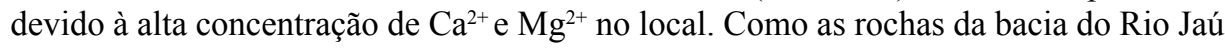


não possuem minerais portadores $\mathrm{de}^{-} \mathrm{Cl}^{-} \mathrm{NO}_{3}^{-}, \mathrm{PO}_{4}{ }^{3-}$ e $\mathrm{SO}_{4}^{2-}$ como constituintes principais, a denudação química ( $\mathrm{t} /$ ano) na bacia do Rio Jaú foi calculada com base na concentração de $\mathrm{Ca}^{2+}, \mathrm{Mg}^{2+}, \mathrm{Na}^{+}, \mathrm{K}^{+}$e $\mathrm{SiO}_{2}$ (solução lixiviada dos minerais que compõem as rochas da bacia). Os resultados indicaram que a bacia do Rio Jaú exporta cerca de 16.000 toneladas de material alterado por ano ao Rio Tietê.

\begin{abstract}
This work evaluated the geochemical denudation and implications in the composition of surface waters from Jaú River basin, six sampling points were established and six field campaigns were carried out in 08/14/2009, 09/17/2009, 10/17/2009, $11 / 20 / 2009,12 / 23 / 2009$ and $01 / 12 / 2010$, which involved the dry and wet periods. The analyses were executed for discharge, temperature, $\mathrm{pH}$, electric conductivity, calcium, magnesium, sodium, potassium, silicon dioxide, alkalinity, chloride, sulfate, phosphate and nitrate. The results indicated that calcium, magnesium and nitrate have similar behavior, i.e. the amount increases upstream (P1 and P3, sediments of Itaqueri Formation and the Middle Hills relief unit) to downstream (P2 and P4, Hillock Elongated and Spikes associated with igneous rocks of the Serra Geral Formation). P5 and P6 also drain the basalts of Serra Geral Formation in Jaú River, where except for $\mathrm{Ca}^{2+}, \mathrm{Mg}^{2+}$ and $\mathrm{Cl}^{-}$all other parameters have a higher concentration at the point P6, near the Tietê River mouth. However, the total cations and anions $\left(\mathrm{t} / \mathrm{km}^{2} /\right.$ year) is greater in point P5, due to the higher concentration of $\mathrm{Ca}^{2+}$ and $\mathrm{Mg}^{2+}$. Because the rocks at Jaú River don't have $\mathrm{Cl}^{-}, \mathrm{NO}_{3}^{-}, \mathrm{PO}_{4}^{3-}$ and $\mathrm{SO}_{4}^{2-}$ bearing minerals as a main constituent, the chemical denudation ( $\mathrm{t} / \mathrm{year}$ ) in Jaú River basin was calculated based on the concentration of $\mathrm{Ca}^{2+}$, $\mathrm{Mg}^{2+}, \mathrm{Na}^{+}, \mathrm{K}^{+}$and $\mathrm{SiO}_{2}$ (leached solution of minerals that make up the basin rocks). The results indicated that the Jaú River basin exports about 16,000 tons of weathered material per year to Tietê River.
\end{abstract}

\section{Introdução}

$\mathrm{O}$ intemperismo age na interface entre a atmosfera e a litosfera e inclui os processos que levam à desagregação das rochas expostas na superfície da Terra. São originadas partículas minerais discretas (produtos residuais) presentes na rocha matriz, que permanecem mais ou menos inalteradas, ao lado de novos minerais formados por intemperismo, além de materiais em solução (Suguio, 2003). Os produtos do intemperismo, rocha alterada e solo, estão sujeitos a outros processos do ciclo supérgeno - erosão, transporte, sedimentação - os quais acabam levando à denudação continental, com o consequente aplainamento do relevo (Teixeira et al., 2000). Os processos denudacionais constituem uma das principais preocupações da ciência geomorfológica e fundamentam, em conjunto com as concepções geotectônicas, as teorias que retratam a evolução do relevo das áreas continentais (Salgado \& Valadão, 2003).

Os processos de intemperismo em áreas continentais não podem ser investigados com base apenas na erosão mecânica, uma vez que a denudação química desempenha papel fundamental no desencadeamento de tais eventos. A composição de íons dissolvidos nas águas dos rios fornece indicações da meteorização química da rocha/solo de uma determinada região (Moreira-Nordemann, 1980 e 1984; Mortatti, et al., 1997; Salgado \& Valadão, 2003; Salgado et al., 2004; Salgado \& Valadão, 2005; Conceição et al., 2007; Mortatti et al., 2008; Sardinha et al., 2008; Sardinha et al., 2010; Sardinha, 2011, Conceição et al., 2012). Além de sua importância nos processos intempéricos, a água é essencial à vida, portanto, todos os organismos vivos, incluindo o ho- mem, dependem dela para a sua sobrevivência. Neste sentido, é necessária uma investigação para determinar a extensão do fenômeno natural versus antropogênico associado com a química elementar das águas superficiais da bacia do Rio Jaú, objeto de estudo do presente trabalho.

A bacia hidrográfica do Rio Jaú compreende $5 \mathrm{mu}$ nicípios com uma população total de 182.136 habitantes, dos quais 3 com sede em seu território e 2 possuindo apenas porções rurais. As demandas de água para o abastecimento público dentre os municípios que compõem a bacia demonstram que a utilização de águas superficiais é realizada nos cinco municípios com 10 pontos de captação. O Rio Jaú nasce na Serra do Tabuleiro, município de Torrinha (SP) e é formado por dois rios principais, o Ribeirão do Bugio e o Ribeirão São João, cujas cabeceiras se encontram nos municípios de Torrinha (SP) e Mineiros do Tietê (SP). Assim, o presente trabalho tem como principal objetivo a análise da denudação geoquímica e suas implicações na química das águas superficiais da bacia do Rio Jaú (SP).

\section{Características gerais da área de estudo}

A bacia hidrográfica do Rio Jaú localiza-se na porção central do Estado, e faz parte da bacia hidrográfica do Tietê/ Jacaré, definida como a Unidade de Gerenciamento de Recursos Hídricos 13 (UGRHI-13). A bacia situa-se entre os paralelos $22^{\circ} 28^{\prime} 02^{\prime \prime}$ e $22^{\circ} 09^{\prime} 37^{\prime \prime}$ de latitude S e meridianos 48³7'29'" e 48 $16^{\circ} 00^{\prime \prime}$ de longitude W, sendo o Rio Jaú o principal curso de água. 
De acordo com a classificação de Köppen, o clima da região da bacia do Rio Jaú é do tipo Cwa, mesotérmico, também chamado de Tropical de Altitude, que é caracterizado por possuir um inverno seco e verão chuvoso. Uma série histórica de precipitações mensais e anuais entre os anos de 1986 e 1999 no município de Jaú (Estação: D5007), entre 1986 e 1999 no município de Mineiros do Tietê (Estação: D5-022), e entre 1985 a 2006 em Dois Córregos (Estação: D5-008) foram obtidas junto ao Sistema de Informações para o Gerenciamento de Recursos Hídricos do Estado de São Paulo (SIGRH, 2009). Os resultados indicam que, entre Novembro a Março, a intensidade pluviométrica média mensal é igual ou superior a $150 \mathrm{~mm}$. Por outro lado, nos meses que correspondem ao inverno, as intensidades pluviométricas médias são bastante reduzidas, aproximadamente $50 \mathrm{~mm}$ (Figura 1a). Rezende, (2009) estudou o comportamento das chuvas na bacia do Rio Jaú entre os períodos de 1984 a 1998 e observou que, as semelhanças dos índices pluviométricos médios mensais e anuais da bacia do Rio Jaú indicam que a precipitação não é a causa das diferenças encontradas do comportamento fluviológico dos rios da bacia.

As temperaturas médias anuais na bacia variam de 21 a $23^{\circ} \mathrm{C}$, com as médias máximas em janeiro situando-se entre 29 e $32^{\circ} \mathrm{C}$ e a média das mínimas em julho de 11 a $13^{\circ} \mathrm{C}$ (FEHIDRO - IPT, 2006). Quanto ao regime de vazões, entre 1981 até 1999 havia um posto fluviométrico no entroncamento do Ribeirão do Bugio com o Rio Jaú (Estação: 5D-029). Os valores entre os períodos de 1981 a 1999 (SIGRH, 2009), demonstram que, o mês de Fevereiro é o de maior vazão média mensal $\left(10,52 \mathrm{~m}^{3} / \mathrm{s}\right)$, e o de Agosto $\left(3,99 \mathrm{~m}^{3} / \mathrm{s}\right)$ o menor (Figura 1b). O Rio Jaú apresenta curva de permanência (Figura 1c), indicando uma vazão específica garantida de aproximadamente $(10 \mathrm{~L} / \mathrm{s} . \mathrm{km}) \mathrm{em} 70 \%$ do tempo ou mais (Rezende, 2009). A Figura 1d apresenta o hidroperíodo e as etapas de pulso (períodos hidrológicos), realizados por Rezende, (2009) onde $\mathrm{hm}$ ou Qm (altura média ou vazão média), determinado como o limite entre os tempos distintos de potamofase (cheia ou acima da vazão média) e limnofase (estiagem ou abaixo da vazão média).
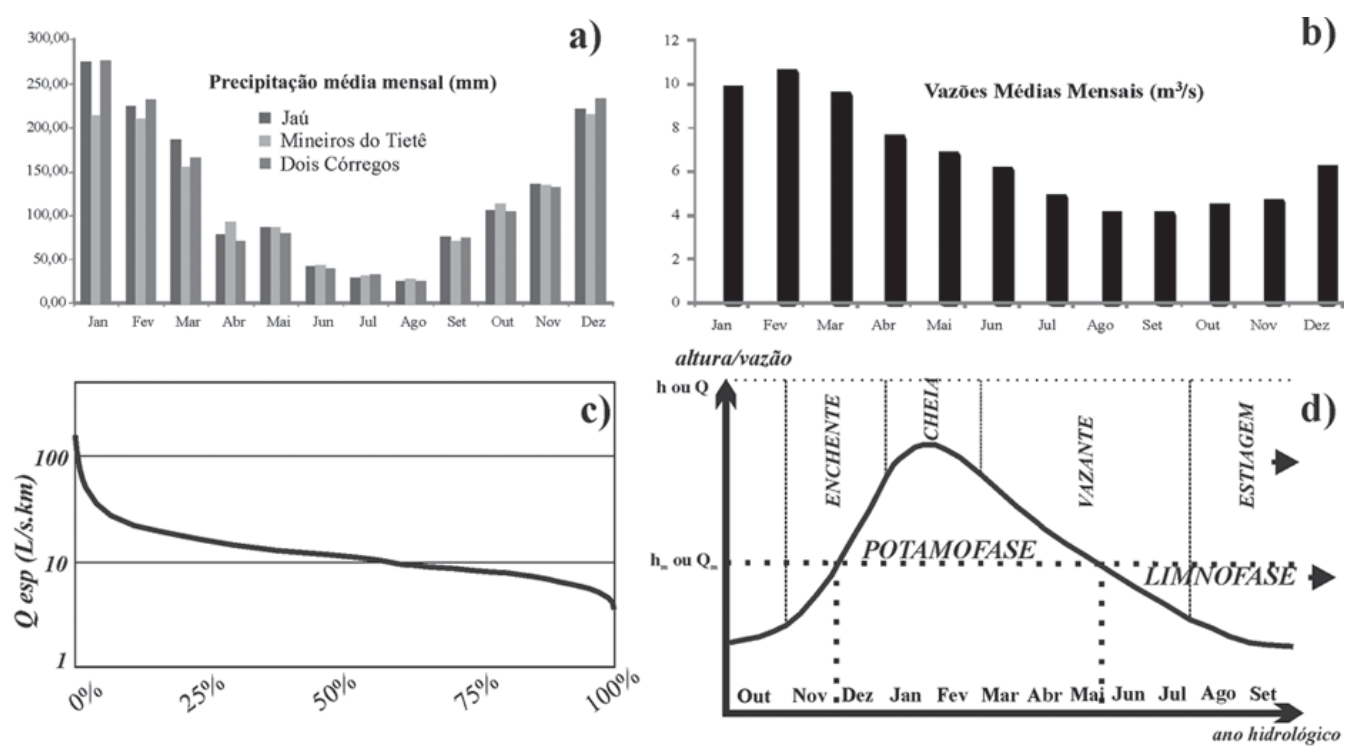

Figura 1 - (a) Precipitações médias mensais (mm) nos municípios que compõem a bacia do Rio Jaú (Jaú, Mineiros do Tietêe e Dois Córregos). (b) Vazões médias mensais $\left(\mathrm{m}^{3} / \mathrm{s}\right)$ no entroncamento do Ribeirão do Bugio com o Rio Jaú. (c) Curva de permanência do Rio Jaú, modificado (Rezende, 2009). (d) Pulso hidrológico (hidroperiodo) da bacia do Rio Jaú, modificado (Rezende, 2009).

Em termos de distribuição das categorias de uso e ocupação do solo na bacia do Rio Jaú (Figura 2), as áreas de vegetação natural $(0,5 \%)$ apresentam-se em pequenos maciços preservados, e nas nascentes do Ribeirão do Bugio, formando as "matas-galerias". As pastagens $(11,5 \%)$ predominam mais fortemente nas cabeceiras dos Ribeirões do Bugio e São João, nas cidades de Dois Córregos e Mineiros do Tiete respectivamente. Dentre as atividades agrícolas $(82,1 \%)$, o cultivo da cana-deaçúcar destaca-se como predominante. Com relação às áreas urbanas, $(5,9 \%)$ a cidade de Jaú é o principal centro urbano da bacia. 


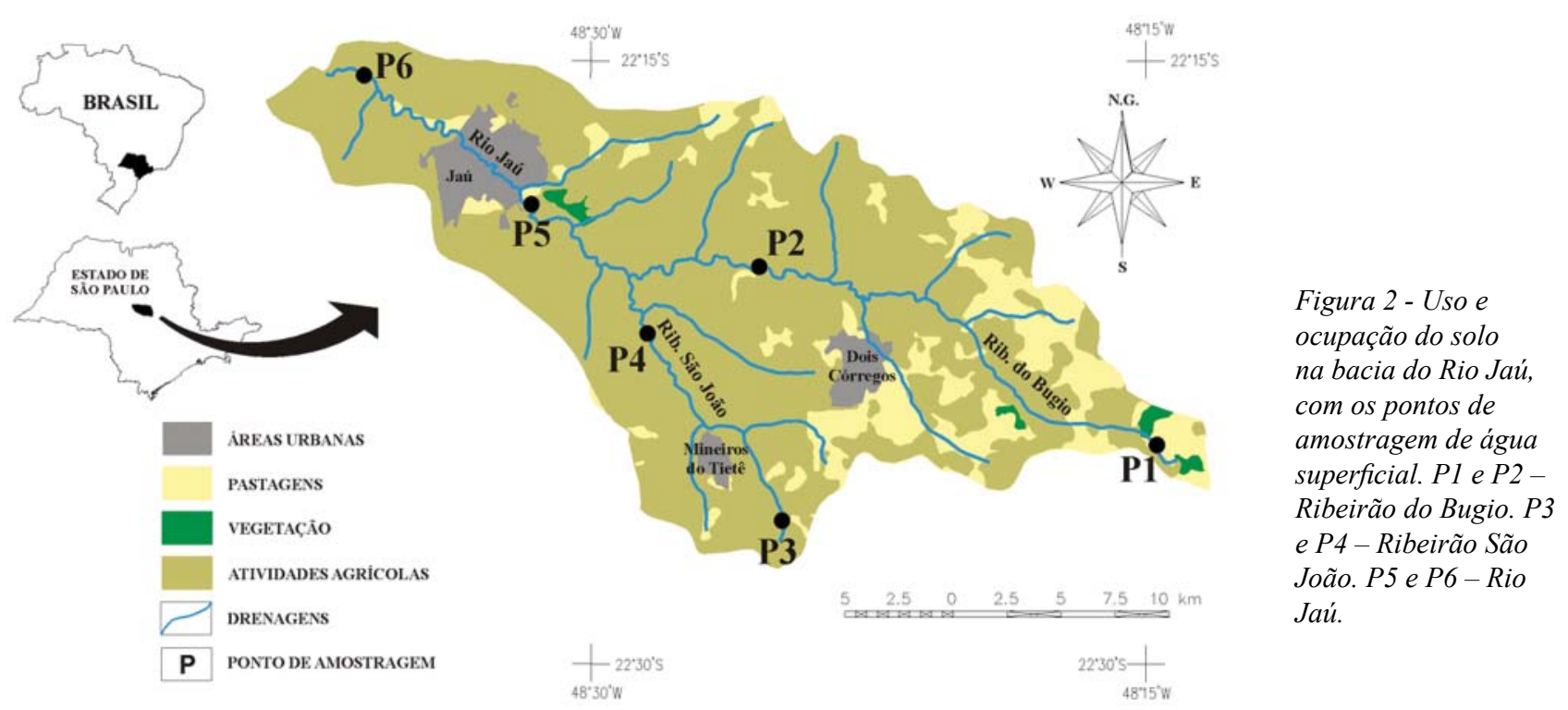

Quanto à geologia (Figura 3), ocorrem unidades da Bacia Sedimentar do Paraná, compostas por rochas basálticas da Formação Serra Geral do Grupo São Bento que se encontram sotopostas por rochas sedimentares da Formação Itaqueri, atribuída ao Grupo Bauru e Pós-Bauru (Riccomini, 1997). Os basaltos da Formação Serra Geral estão sotopostos aos sedimentos dos Grupos Bauru e Caiuá, que ocupam praticamente toda a porção ocidental do estado de São Paulo, condicionando a ocorrência de basaltos em afloramentos dispostos em faixas ao longo da rede de drenagem (Squisato et al., 2009). Constituem a Formação Itaqueri membros alternados de arenitos com cimento argiloso, folhelhos e conglomerados (Riccomini, 1997). Os arenitos têm granulometria variável, de muito fina e siltítica até grossa, são eventualmente silicificados, podendo ser arcoseanos.

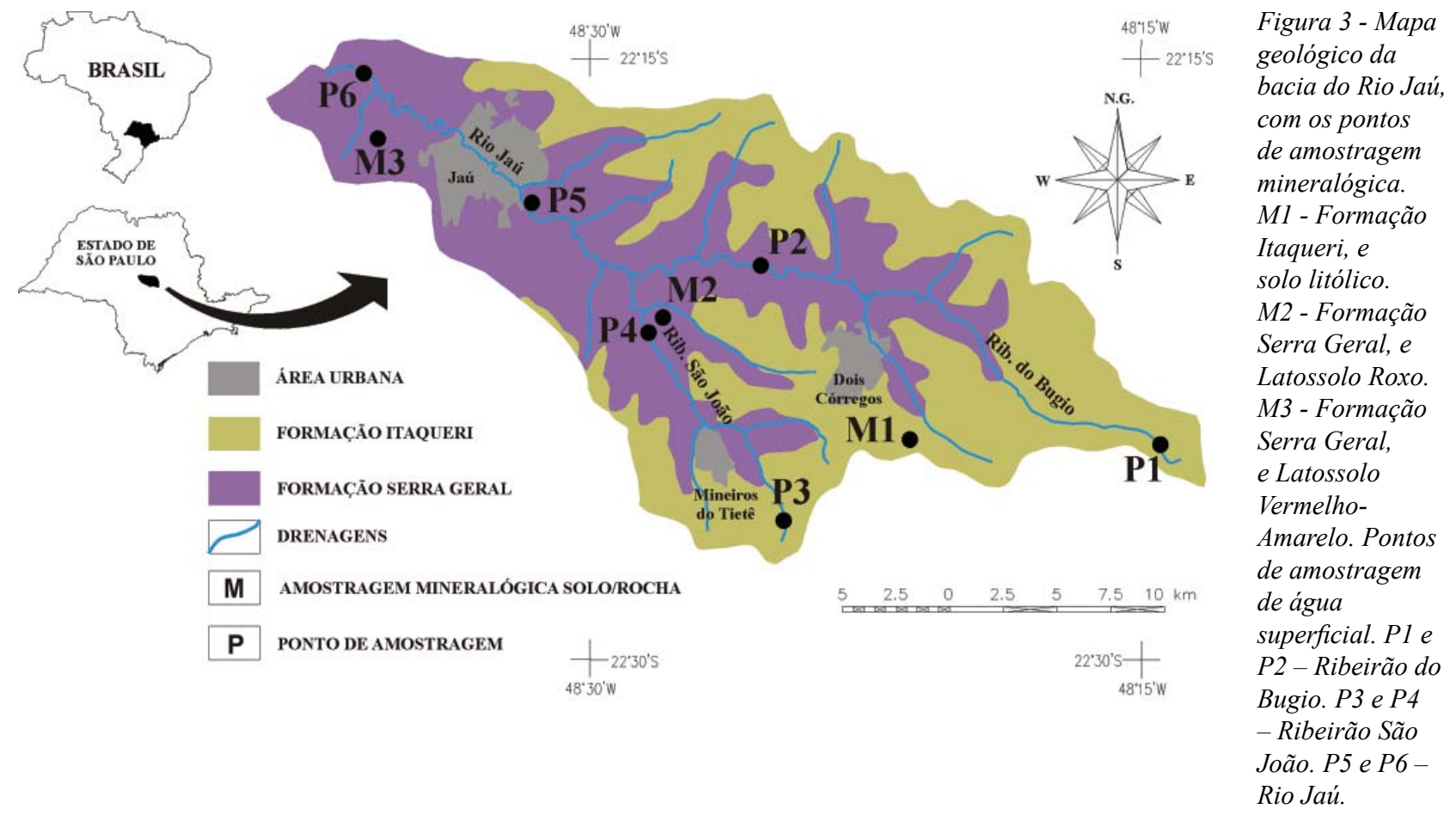


A bacia do Rio Jaú está inserida na Província Geomorfológica das Cuestas Basálticas, segundo a subdivisão geomorfológica do Estado de São Paulo (IPT, 1981). Esta província geomorfológica apresenta-se sob a forma de diversos planaltos e transições interplanálticas, configurando um vasto interflúvio, que avança sobre a Depressão Periférica. Quanto ao sistema de relevo, ocorrem principalmente as Colinas Médias, Colinas Amplas e o sistema de Morrotes Alongados e Espigões. Os pontos P1 e P3 correspondem aos sedimentos da Formação Itaqueri e a unidade de relevo Colinas Médias, onde se identificam interflúvios com áreas de aproximadamente $2,5 \mathrm{~km}^{2}$, topos aplainados e vertentes com perfis retilíneos. Os pontos P2 e P4 são caracterizados por Morrotes Alongados e Espigões e ocorrem associados às litologias da Formação Serra Geral, onde predominam interflúvios com orientação preferencial da calha do Rio Tietê, topos angulosos a achatados e vertentes com perfis retilíneos. Já os pontos localizados no Rio Jaú (P5 e P6) que também drenam os basaltos da Formação Serra Geral estão localizados em áreas onde predominam Morrotes Alongados e Espigões e Colinas Amplas com topos extensos e aplainados.

Os tipos de solos estão diretamente relacionados ao relevo regional e ao substrato rochoso. Esta influência manifesta-se através da interação entre as formas de relevo e a dinâmica da água. Assim, em relevos de colinas e planícies, há uma tendência à infiltração da água que, ao entrar em contato com o substrato, favorece o desenvolvimento de solos mais profundos (Latossolos), enquanto que em relevos de alta declividade, a ação do escoamento superficial sobrepõe-se à infiltração, levando à formação de solos rasos (Litólicos).

\section{Materiais e métodos}

As amostras de rochas e solos foram encaminhadas para a análise mineralógica no Laboratório de Difração de Raios $\mathrm{X}$ do Departamento de Petrologia e Metalogenia (DPM) do IGCE da UNESP de Rio Claro (SP). Aproximadamente $1 \mathrm{~g}$ de cada amostra foi devidamente acondicionada em porta amostra sendo efetuada a análise da amostra total dos minerais presentes. As análises mineralógicas por Difração de Raios X (DRX) foram realizadas em difratômetro marca Siemens D 5000. A interpretação dos difratogramas foi realizada no software X'Pert High Score Plus da Panalytical.

Para avaliar a composição química das águas superficiais, foram realizadas seis coletas: 14/08/2009, 17/09/2009, 17/10/2009, 20/11/2009, 23/12/2009 e 12/01/2010. As águas foram coletadas no centro da seção transversal, com uso de balde de polietileno. As medidas de temperatura da água, $\mathrm{pH}$ e condutividade foram feitas com uso de: termômetro Digital Pocket CE da Onda Científica Ltda; medidor de $\mathrm{pH}$ da Hanna Instruments e condutivímetro DIST 4 da Hanna Instruments. As amostras foram acondicionadas em frascos de polietileno, colocados em isopor com gelo e transportadas ao Laboratório de Isótopos e Hidroquímica (LABIDRO) do Departamento de Petrologia e Metalogenia (DPM) do IGCE da UNESP de Rio Claro (SP), onde foram filtradas em membranas Millipore de $0,45 \mu \mathrm{m}$ e conservadas com ácido nítrico $\left(\mathrm{HNO}_{3}^{-}\right)$e ácido clorídrico $\left(\mathrm{HCl}^{-}\right)$, até atingir um $\mathrm{pH} \leq 2,0$.

Uma parte das alíquotas preservadas foi analisada no próprio LABIDRO: $\mathrm{SO}_{4}^{2-}, \mathrm{PO}_{4}^{3-}, \mathrm{NO}_{3}^{-}, \mathrm{Cl}^{-}$e $\mathrm{SiO}_{2}$. Sulfato (método turbidimétrico do sulfato de bário, de 0 a $70 \pm 0,9$ $\mathrm{mg} / \mathrm{L}$ ), fosfato orgânico dissolvido (método do ácido ascórbico, de 0 a $3 \pm 0,01 \mathrm{mg} / \mathrm{L}$ ), nitrato (método de redução de cádmio, de 0 a $30 \pm 0,8 \mathrm{mg} / \mathrm{L}$ ), cloreto (método de tiocianato mercúrico, de 0 a $20 \pm 0,3 \mathrm{mg} / \mathrm{L}$ ) e sílica (método do silício molibdato de 0 a $100 \pm 0,45 \mathrm{mg} / \mathrm{L}$ ), foram quantificados por espectrofotometria com o equipamento DR 2000 da Hach Company (HACH, 1992). Outra parte das alíquotas foi enviada para o Laboratório de Geoquímica (LABOGEO) do DPM/IGCE da UNESP de Rio Claro (SP) onde foram

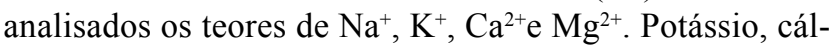
cio e magnésio foram quantificados por Espectrometria de Emissão em Plasma Indutivamente Acoplado (ARL 3410). Já a determinação de sódio foi realizada por Espectrofotometria de Absorção Atômica com Chama (FAAS - $G B C$ 608). Os teores de sólidos totais dissolvidos (STD) foram calculados com base na somatória $\left(\mathrm{Ca}^{2+}, \mathrm{Mg}^{2+}, \mathrm{Na}^{+}, \mathrm{K}^{+}\right.$, $\mathrm{SiO}_{2}, \mathrm{Cl}^{-}, \mathrm{PO}_{4}^{3-}, \mathrm{SO}_{4}{ }^{2-}$ e $\mathrm{NO}_{3}^{-}$) dos constituintes analisados neste trabalho.

A vazão do ponto P1 foi medida de acordo com a metodologia descrita por Hermes \& Silva (2004), utilizando-se uma régua limnimétrica de leitura da medida do nível do rio, uma trena, um objeto flutuador e um cronômetro, sendo as variáveis colocadas posteriormente na equação 1 :

$$
Q=\frac{A x D x C}{T}
$$

Onde: $Q=$ vazão $\left(\mathrm{m}^{3} / \mathrm{s}\right) ; A=$ área da seção transversal do rio $\left(\mathrm{m}^{2}\right) ; D=$ distância usada para medir a velocidade do rio $(\mathrm{m}) ; C=$ coeficiente de correção: ( 0,8 para rios com fundo rochoso e 0,9 para rios com fundo lodoso); $T=$ tempo (s) gasto pelo objeto flutuador para atravessar a distância $D$.

De acordo com Tucci (2001), há uma maneira de se calcular a vazão das sub-bacias, levando em consideração a existência de dados de vazão, a vazão de cada sub-bacia e a proporção de área entre a bacia de drenagem e cada subbacia. Utilizando a área total da bacia do Rio Jaú (Ap), os dados de vazão medida em campo no ponto $\mathrm{P} 1(Q l)$ e a área de influência no ponto $\mathrm{P} 1(\mathrm{Al})$, calculou-se através da equação (2), a vazão do exutório da bacia $(Q p)$ para os períodos de amostragem, e consequentemente a vazão de contribuição $(Q l)$ de cada ponto de coleta. 


$$
Q l=Q p \cdot \frac{A l}{A p}
$$

Onde: Qp vazão do exutório da bacia $\left(\mathrm{m}^{3} / \mathrm{s}\right) ; A p=$ área total da bacia $\left(\mathrm{m}^{2}\right) ; A l=$ área de cada sub-bacia $\left(\mathrm{m}^{2}\right)$.

$\mathrm{O}$ valor do fluxo anual de cátions e ânions $\left(\mathrm{t} / \mathrm{km}^{2} / \mathrm{ano}\right)$ calculado para a bacia do Rio Jaú, foi realizada pela metodologia descrita por (Moreira-Nordemann, 1980, 1984), utilizando a média ponderada de cátions e ânions, a área e a vazão média de cada ponto de amostragem: $\mathrm{P} 1=6,72 \mathrm{~km}^{2} \mathrm{e} 0,13 \mathrm{~m}^{3} / \mathrm{s}, \mathrm{P} 2=185,01 \mathrm{~km}^{2}$ e $3,56 \mathrm{~m}^{3} / \mathrm{s}, \mathrm{P} 3=6,98 \mathrm{~km}^{2}$ e $0,13 \mathrm{~m}^{3} / \mathrm{s}, \mathrm{P} 4=63,04 \mathrm{~km}^{2}$ e $1,21 \mathrm{~m}^{3} / \mathrm{s}$, $\mathrm{P} 5=355,18 \mathrm{~km}^{2}$ e $6,84 \mathrm{~m}^{3} / \mathrm{s}$ e $\mathrm{P} 6=467,16 \mathrm{~km}^{2}$ e $9,0 \mathrm{~m}^{3} / \mathrm{s}$.

Para se obter as correlações lineares de Pearson entre os parâmetros quantificados neste trabalho, utilizou-se o software Statistica for Windons $4.3^{T M}$. A análise de correlação linear de Pearson é um método estatístico bastante utilizado para identificar o comportamento de uma variável em relação à outra, permitindo verificar se as variáveis são dependentes ou independentes.

\section{Resultados e discussões}

\section{Análise mineralógica por Difração de Raios $\mathrm{X}$}

Ao todo, foram analisadas seis amostras por difração de raios X (Figura 4). O difratograma na Figura 4a é referente à amostra de rocha da Formação Itaqueri (M1), cujos minerais encontrados correspondem à mineralogia composta de quazto (Q) e feldspato potássico (Fk), apresentando ainda alguns níveis de albita $(\mathrm{Pl})$ e caulinita $(\mathrm{K})$. A Figura 4b mostra o difratograma obtido para a amostra de horizonte $\mathrm{C}$ do solo (M1), referente à alteração da rocha da Formação Itaqueri, que também apresenta picos bem marcados referentes ao (Q) quartzo. Feldspato potássico (Fk) e caulinita (K) são os outros dois principais minerais encontrados na amostra de solo.
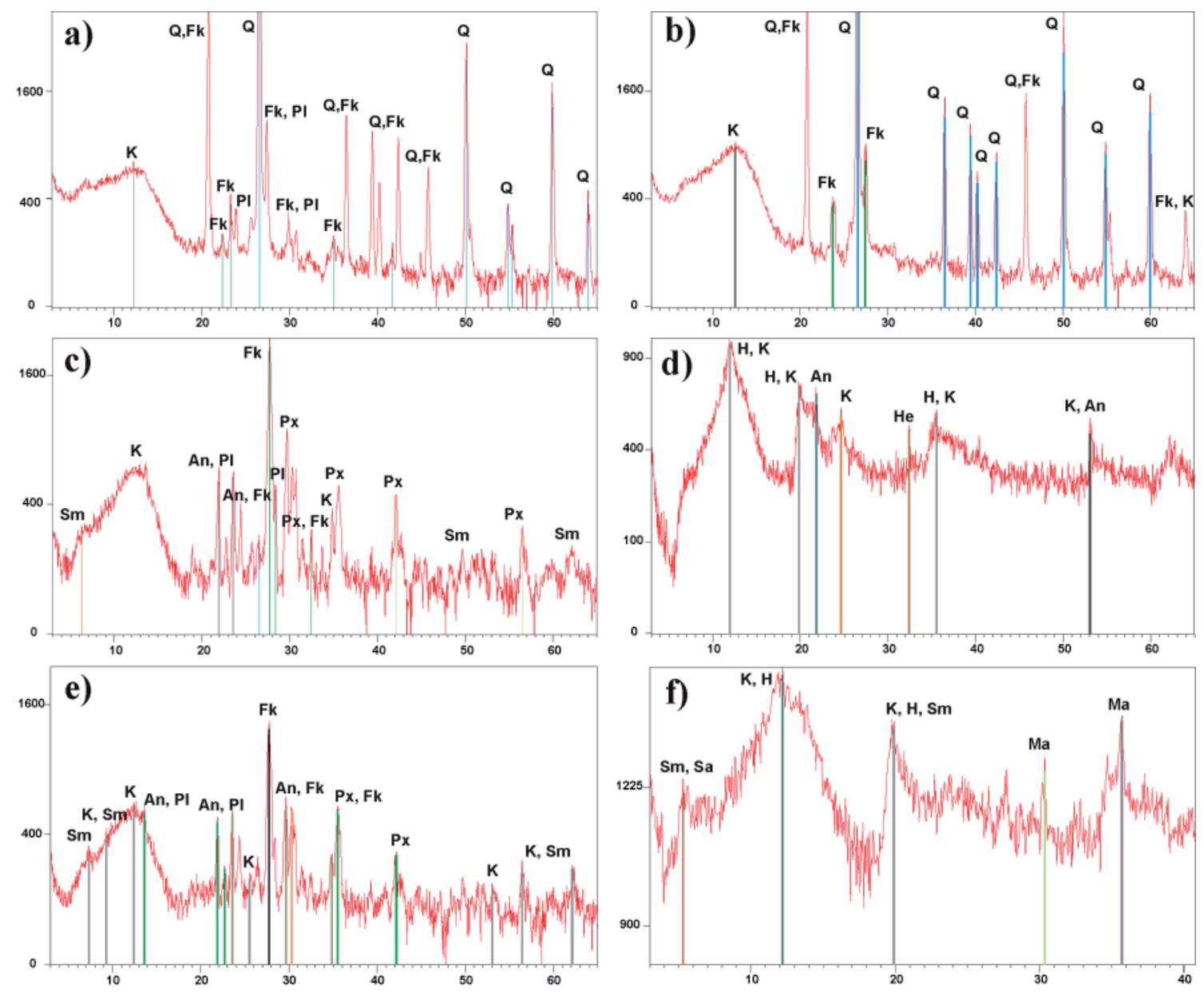

Figura 4 - Difratogramas das rochas e solos analisados na bacia do Rio Jaú. (a) Formação Itaquerí M1. (b) Solo, horizonte C, resultante da alteração da rocha M1. (c) Formação Serra Geral M2. (d) Solo, horizonte C, resultante da alteração da rocha M2. (e) Formação Serra Geral M3. (f) Solo, horizonte C, resultante da alteração da rocha M3. 
Tabela 1 - Resultados dos parâmetros físicos e físico-químicos analisados nas águas fluviais da bacia do Rio Jaú.

\begin{tabular}{|c|c|c|c|c|c|c|c|c|c|c|c|c|c|c|}
\hline & ${ }^{1} \mathbf{Q}$ & ${ }^{2} \mathrm{C}$ & $\mathbf{p H}$ & & $\mathrm{Ca}^{2+}$ & $\mathrm{Mg}^{2+}$ & $\mathrm{Na}^{+}$ & $\mathbf{K}^{+}$ & $\mathrm{SiO}_{2}$ & $\mathrm{Cl}^{-}$ & $\mathrm{PO}_{4}^{3-}$ & $\mathrm{SO}_{4}^{2-}$ & $\mathrm{NO}_{3}^{-}$ & ${ }^{3} \mathrm{STD}$ \\
\hline coleta & & & & $\left({ }^{\circ} \mathrm{C}\right)$ & \multicolumn{10}{|c|}{$(\mathrm{mg} / \mathrm{L})$} \\
\hline \multicolumn{15}{|c|}{ Ponto 1 - Ribeirão do Bugio: $22^{\circ} 23^{\prime} 59^{\prime \prime} \mathrm{S} \mathrm{e} 48^{\circ} 15^{\prime} 37^{\prime \prime} \mathrm{W}$} \\
\hline $17 / 09 / 09$ & 0,09 & 2 & 6,09 & 23,30 & 2,28 & 0,89 & 0,80 & 1,21 & 4,40 & 0,10 & 0,12 & 4,00 & 0,60 & 14,4 \\
\hline $17 / 10 / 09$ & 0,10 & 4 & 6,69 & 21,60 & 3,13 & 1,26 & 0,76 & 1,15 & 2,30 & 0,00 & 0,09 & 3,00 & 11,10 & 22,79 \\
\hline 20/11/09 & 0,13 & 2 & 6,17 & 26,50 & 1,30 & 0,49 & 0,50 & 0,57 & 0,60 & 0,00 & 0,12 & 3,00 & 1,80 & 8,38 \\
\hline 23/12/09 & 0,14 & 3 & 6,47 & 23,40 & 2,24 & 0,84 & 0,70 & 0,78 & 3,60 & 0,50 & 0,33 & 2,00 & 0,80 & 11,79 \\
\hline $12 / 01 / 10$ & 0,23 & 2 & 6,06 & 24,10 & 2,10 & 0,77 & 0,70 & 0,96 & 1,70 & 0,30 & 0,30 & 5,00 & 0,60 & 12,43 \\
\hline \multicolumn{15}{|c|}{ 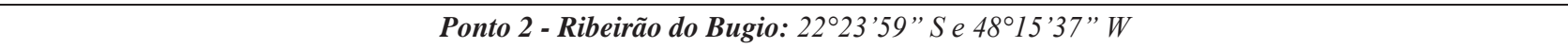 } \\
\hline $14 / 08 / 09$ & 2,54 & 53 & 6,50 & 20,00 & 6,37 & 2,66 & 3,21 & 1,72 & 16,90 & 1,60 & 0,56 & 1,00 & 8,80 & 42,82 \\
\hline $17 / 09 / 09$ & 2,55 & 41 & 6,51 & 23,50 & 8,17 & 2,89 & 2,59 & 1,67 & 13,00 & 1,20 & 0,62 & 4,00 & 7,80 & 41,94 \\
\hline 17/10/09 & 2,75 & 25 & 6,66 & 22,10 & 7,91 & 3,18 & 4,15 & 1,75 & 13,70 & 1,20 & 0,42 & 1,00 & 10,50 & 43,81 \\
\hline 23/12/09 & 3,87 & 48 & 7,37 & 23,10 & 7,24 & 3,07 & 2,67 & 1,54 & 17,30 & 0,00 & 0,58 & 4,00 & 1,20 & 37,60 \\
\hline $12 / 01 / 10$ & 6,20 & 35 & 6,43 & 24,00 & 6,75 & 2,88 & 1,91 & 1,53 & 13,60 & 0,50 & 0,43 & 2,00 & 1,70 & 31,30 \\
\hline \multicolumn{15}{|c|}{ 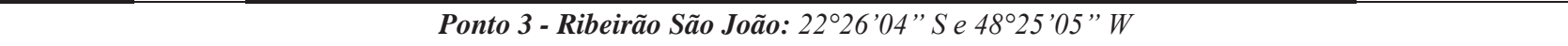 } \\
\hline $14 / 08 / 09$ & 0,10 & 25 & 6,15 & 17,50 & 5,21 & 1,65 & 1,36 & 2,40 & 9,00 & 1,40 & 0,63 & 2,00 & 0,50 & 24,15 \\
\hline 17/09/09 & 0,10 & 22 & 6,10 & 20,30 & 5,98 & 1,93 & 1,35 & 2,90 & 9,10 & 1,40 & 0,43 & 2,00 & 0,70 & 25,79 \\
\hline 17/10/09 & 0,10 & 18 & 6,36 & 20,50 & 5,49 & 2,01 & 1,35 & 4,23 & 8,10 & 2,20 & 0,44 & 2,00 & 8,70 & 34,52 \\
\hline 20/11/09 & 0,13 & 47 & 6,37 & 23,80 & 9,04 & 2,67 & 1,32 & 4,16 & 4,20 & 1,70 & 0,87 & 8,00 & 2,10 & 34,06 \\
\hline 23/12/09 & 0,15 & 37 & 6,56 & 22,60 & 6,07 & 1,92 & 1,30 & 3,98 & 12,30 & 1,80 & 0,56 & 4,00 & 0,50 & 32,43 \\
\hline $12 / 01 / 10$ & 0,23 & 10 & 6,18 & 23,70 & 5,56 & 1,75 & 1,35 & 3,52 & 2,40 & 1,70 & 0,30 & 2,00 & 0,80 & 19,38 \\
\hline \multicolumn{15}{|c|}{ Ponto 4 - Ribeirão São João: $22^{\circ} 22^{\prime} 51^{\prime \prime}$ S e 48²8'01 " W } \\
\hline $14 / 08 / 09$ & 0,87 & 40 & 6,44 & 21,00 & 5,31 & 2,19 & 3,25 & 1,46 & 15,30 & 1,00 & 0,84 & 3,00 & 1,10 & 33,45 \\
\hline $17 / 09 / 09$ & 0,87 & 33 & 6,26 & 22,90 & 5,90 & 2,48 & 3,47 & 1,64 & 13,20 & 1,60 & 0,56 & 2,00 & 8,00 & 38,85 \\
\hline 23/12/09 & 1,32 & 39 & 7,18 & 23,20 & 6,55 & 2,79 & 2,63 & 1,59 & 1,60 & 0,80 & 0,58 & 3,00 & 12,00 & 31,54 \\
\hline $12 / 01 / 10$ & 2,11 & 37 & 6,34 & 23,80 & 7,17 & 2,80 & 2,54 & 1,59 & 2,50 & 0,80 & 0,34 & 4,00 & 1,20 & 22,94 \\
\hline \multicolumn{15}{|c|}{ Ponto 5 - Rio Jaú: $22^{\circ} 18^{\prime} 09^{\prime \prime} \mathrm{S}$ e 4832’25” W } \\
\hline $14 / 08 / 09$ & 4,87 & 55 & 6,34 & 21,70 & 7,71 & 3,08 & 3,64 & 1,56 & 0,60 & 1,30 & 0,28 & 3,00 & 1,30 & 22,47 \\
\hline $17 / 09 / 09$ & 4,90 & 54 & 6,28 & 23,40 & 8,08 & 3,32 & 4,00 & 1,76 & 0,50 & 9,40 & 0,82 & 3,00 & 13,60 & 44,48 \\
\hline $17 / 10 / 09$ & 5,28 & 40 & 6,97 & 23,50 & 157,14 & 7,49 & 3,50 & 1,91 & 1,20 & 0,90 & 0,40 & 2,00 & 9,00 & 183,54 \\
\hline 20/11/09 & 6,67 & 55 & 6,48 & 27,00 & 147,55 & 7,50 & 3,70 & 1,93 & 0,70 & 2,10 & 0,81 & 4,00 & 1,00 & 169,29 \\
\hline 23/12/09 & 7,43 & 59 & 7,26 & 24,60 & 129,57 & 7,20 & 3,45 & 1,70 & 2,00 & 1,50 & 0,17 & 4,00 & 7,50 & 157,09 \\
\hline $12 / 01 / 10$ & 11,91 & 43 & 6,46 & 24,80 & 122,05 & 6,36 & 2,13 & 1,42 & 2,00 & 0,90 & 0,24 & 4,00 & 1,40 & 140,50 \\
\hline \multicolumn{15}{|c|}{ 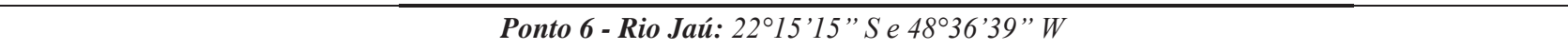 } \\
\hline $14 / 08 / 09$ & 6,41 & 82 & 6,45 & 22,00 & 9,81 & 3,78 & 6,28 & 2,14 & 1,80 & 2,60 & 0,96 & 5,00 & 8,20 & 40,57 \\
\hline $17 / 09 / 09$ & 6,44 & 68 & 6,36 & 25,60 & 10,85 & 4,03 & 4,27 & 1,98 & 14,80 & 1,80 & 0,43 & 3,00 & 10,80 & 51,96 \\
\hline 17/10/09 & 6,94 & 61 & 6,99 & 24,30 & 10,38 & 4,06 & 4,89 & 2,25 & 17,50 & 1,80 & 0,52 & 5,00 & 12,30 & 58,70 \\
\hline 20/11/09 & 8,77 & 79 & 6,40 & 27,90 & 11,45 & 4,37 & 5,85 & 2,24 & 1,40 & 2,40 & 0,26 & 4,00 & 1,60 & 33,57 \\
\hline 23/12/09 & 9,77 & 75 & 7,37 & 26,00 & 118,64 & 7,49 & 4,75 & 1,93 & 19,30 & 2,00 & 0,28 & 4,00 & 9,60 & 167,99 \\
\hline $12 / 01 / 10$ & 15,66 & 55 & 6,53 & 25,20 & 10,72 & 4,16 & 3,28 & 1,80 & 20,20 & 1,20 & 0,30 & 4,00 & 3,10 & 48,76 \\
\hline
\end{tabular}

${ }^{1} Q=\operatorname{Vazão}\left(\mathrm{m}^{3} / \mathrm{s}\right):$ P1 (vazão medida em campo), P2, P3, P4, P5 e P6 (vazão estimada de acordo com a equação 2$) ;{ }^{2} \mathrm{C}=$ Condutividade $(\mu \mathrm{S} / \mathrm{cm}) ;{ }^{3} \mathrm{STD}=$ Sólidos Totais Dissolvidos ( $\Sigma$ constituintes analisados $)$. 
Na Figura 4c pode-se observar à mineralogia da amostra de rocha basáltica da Formação Serra Geral (M2), feldspato potássico (Fk), anortoclásio (An) e augita (Px) foram os principais minerais identificados, ao passo que esmectita $(\mathrm{Sm})$ e caulinita $(\mathrm{K})$ foram observadas em menores quantidades. $\mathrm{O}$ difratograma da amostra de solo, alteração da rocha basáltica (M2 - Figura 4d), mostra a ocorrência de argilominerais, relacionadas ao processo de alteração dos principais óxidos $\left(\mathrm{Na}_{2} \mathrm{O}, \mathrm{CaO}, \mathrm{K}_{2} \mathrm{O}\right.$ e $\mathrm{MgO}$ ), bem como ao grau de alteração do material, ocorrência de picos de caulinita $(\mathrm{K})$, haloisita $(\mathrm{H}) \mathrm{e}$ hematita $(\mathrm{He})$ comumente relacionado à pedogênese.

As amostras de rocha da Formação Serra Geral (M3) e seu produto de alteração (Figuras $4 \mathrm{e}$ e $4 \mathrm{f}$ ) possuem em comum argilominerais de caulinita (K) e esmectita (Sm). O difratograma de solo (Figura 4f) apresenta argilominerais de haloisita $(\mathrm{H})$, magnetita $(\mathrm{Ma})$ e saponita $(\mathrm{Sa})$, devido a alteração de minerais de magnésio e comumente formada pela alteração de minerais que contém óxido de ferro, respectivamente.

Os resultados demonstram que, o clima na bacia do Rio Jaú (pluviosidade média de 1500,00 mm/ano e temperatura média de $23^{\circ} \mathrm{C}$ ) causa uma alteração química moderada nos minerais primários (feldspato potássico, anortoclásio, augita, albita e anortita), com a geração de minerais secundários (caulinita, haloisita, saponita e esmectita). Neste sentido, ocorre na bacia do Rio Jaú os processos de monossialitização, geração de argilo minerais 1:1 (caulinita, haloisita e saponita), e bissilialitização com geração de argilo minerais 2:1(esmectita). Em geral, as reações de alteração das rochas liberam como solução lixiviada $\mathrm{Na}^{+}, \mathrm{K}^{+}, \mathrm{Ca}^{2+}, \mathrm{Mg}^{2+}$ e $\mathrm{SiO}_{2}$, consomem $\mathrm{CO}_{2}$ da atmosfera, e produzem $\mathrm{HCO}_{3}{ }^{-}$em solução formando argilominerais, permanecendo como produtos secundários em solos.

\section{Química das águas superficiais}

Na Tabela 1 constam os resultados obtidos para os parâmetros físicos e físico-químicos das águas fluviais nos seis pontos de amostragem da bacia do Rio Jaú. Os valores apresentados na Tabela 1 indicam que as vazões em todos os pontos da amostragem são mais elevadas nos meses de Novembro, Dezembro e Janeiro do que nos demais meses de amostragem, neste caso Agosto, Setembro e Outubro. Assim, foram considerados como período seco (vazante e estiagem) as coletas dos dias 14/08/2009, 17/09/2009, 17/10/2009 e período chuvoso (enchente e cheia) as coletas dos dias 20/11/2009, 23/12/2009 e 12/01/2010.

Na Tabela 2 consta a média dos parâmetros físicos e a média ponderada dos parâmetros químicos analisados durante todo o período de coleta. A média ponderada foi calculada a partir da equação 3 (Moreira-Nordemann, 1980, 1984):

$$
C_{E}=\frac{\sum_{i=1}^{n} C_{i} \cdot Q_{i}}{\sum_{i=1}^{n} Q_{i}}
$$

Onde: $C_{E}=$ média ponderada do parâmetro $(\mathrm{mg} / \mathrm{L}) ; C i$ = concentração do parâmetro na i-ésima amostra $(\mathrm{mg} / \mathrm{L}) ; Q i$ = vazão do rio durante a coleta da i-ésima amostra $\left(\mathrm{m}^{3} / \mathrm{s}\right)$.

Tabela 2 - Valores médios e média ponderada dos parâmetros analisados durante todo o período de coleta na bacia do Rio Jaú.

\begin{tabular}{|c|c|c|c|c|c|c|c|c|c|c|c|c|c|}
\hline & $\Omega^{1}$ & $C^{2}$ & $p H$ & $\mathrm{Ca}^{2+}$ & $M^{2+}$ & $\mathrm{Na}^{+}$ & $\boldsymbol{K}^{+}$ & $\mathrm{SiO}_{2}$ & $\mathrm{Cl}^{-}$ & $\mathrm{PO}_{4}^{3-}$ & $\mathrm{SO}_{4}^{2-}$ & $\mathrm{NO}_{3}^{-}$ & $S T D^{3}$ \\
\hline & $\mathbf{Q}$ & $C^{2}$ & & \multicolumn{10}{|c|}{ Média $(\mathrm{mg} / \mathrm{L})$} \\
\hline$P 1$ & 0,13 & 2,67 & 6,28 & 2,22 & 0,85 & 0,71 & 0,96 & 2,63 & 0,20 & 0,19 & 3,17 & 3,78 & 14,71 \\
\hline$P 2$ & 3,56 & 43,67 & 6,66 & 7,56 & 3,02 & 3,31 & 1,71 & 15,27 & 1,02 & 0,49 & 2,17 & 5,18 & 39,72 \\
\hline P3 & 0,13 & 26,50 & 6,29 & 6,23 & 1,99 & 1,34 & 3,53 & 7,52 & 1,70 & 0,54 & 3,33 & 2,22 & 28,39 \\
\hline P4 & 1,21 & 34,17 & 6,58 & 6,30 & 2,59 & 2,89 & 1,60 & 6,00 & 1,20 & 0,51 & 2,67 & 5,73 & 29,49 \\
\hline P5 & 6,84 & 51,00 & 6,63 & 95,35 & 5,83 & 3,40 & 1,71 & 1,17 & 2,68 & 0,45 & 3,33 & 5,63 & 119,56 \\
\hline \multirow[t]{2}{*}{ P6 } & 9,00 & 70,00 & 6,68 & 28,64 & 4,65 & 4,89 & 2,06 & 12,50 & 1,97 & 0,46 & 4,17 & 7,60 & 66,93 \\
\hline & & & & \multicolumn{10}{|c|}{ Média ponderada $(\mathrm{mg} / \mathrm{L})$} \\
\hline$P 1$ & --- & --- & ---- & 2,17 & 0,82 & 0,70 & 0,93 & 2,44 & 0,23 & 0,21 & 3,40 & 3,04 & 13,94 \\
\hline$P 2$ & ---- & ---- & ---- & 7,46 & 3,02 & 3,13 & 1,68 & 15,17 & 0,89 & 0,47 & 2,19 & 4,21 & 38,23 \\
\hline P3 & ---- & ---- & ---- & 6,22 & 1,97 & 1,34 & 3,59 & 6,80 & 1,71 & 0,51 & 3,34 & 1,92 & 27,40 \\
\hline P4 & ---- & ---- & ---- & 6,47 & 2,64 & 2,81 & 1,60 & 4,89 & 1,11 & 0,48 & 2,88 & 5,20 & 28,08 \\
\hline P5 & ---- & ---- & ---- & 104,89 & 6,09 & 3,20 & 1,67 & 1,34 & 2,27 & 0,41 & 3,50 & 4,86 & 128,24 \\
\hline P6 & ---- & ---- & ---- & 30,22 & 4,72 & 4,64 & 2,01 & 13,81 & 1,85 & 0,41 & 4,13 & 6,74 & 68,55 \\
\hline
\end{tabular}

${ }^{1} Q=\operatorname{Vazão}\left(\mathrm{m}^{3} / \mathrm{s}\right) ;{ }^{2} \mathrm{C}=$ Condutividade $(\mu \mathrm{S} / \mathrm{cm}) ;{ }^{3} \mathrm{STD}=$ Sólidos Totais Dissolvidos. 
Os menores valores de condutividade elétrica foram obtidos no Ribeirão do Bugio (P1), enquanto que os maiores foram caracterizados sempre no Rio Jaú (P6), após a cidade de Jaú (Tabelas 1 e 2). Em nenhuma amostra foram encontrados valores acima do limite superior esperado para águas naturais de $100 \mu \mathrm{S} / \mathrm{cm}$ (Hermes \& Silva, 2004). Acredita-se que os valores mais acentuados possam ser atribuídos a descargas de efluentes e às atividades agrícolas realizadas na bacia do Rio Jaú, no entanto, o intemperismo das rochas também pode contribuir para elevar os valores de condutividade nas águas.

$\mathrm{Na}$ bacia, os valores obtidos para $\mathrm{pH}$ em todos os pontos de amostragem indicam que as águas são geralmente neutras, encontrando-se dentro da faixa de proteção da vida aquática, segundo a Legislação Federal (Resolução CONAMA n ${ }^{\circ}$ 357/05) (CONAMA, 2010) e Estadual (Decreto n ${ }^{\circ} 8.468 / 76$ ) (CETESB, 2010) para rios de Classe 2 (Ribeirão do Bugio e São João) e Classe 3 (Rio Jaú), conforme são enquadrados os rios da bacia do Rio Jaú, de acordo com o Decreto Estadual $10.755 / 77$. Os maiores valores de $\mathrm{pH}$ ocorreram nos meses de outubro e dezembro de 2009. Além disso, os menores valores de $\mathrm{pH}$ foram obtidos nas cabeceiras dos Ribeirões Bugio e São João e os maiores valores no Rio Jaú (P6).

Os valores obtidos para os principais cátions e ânions (Tabela 2) indicam a seguinte tendência $\mathrm{Ca}^{2+}>\mathrm{Mg}^{2+}>\mathrm{Na}^{+}$ $>\mathrm{K}^{+}$encontrada para os cátions e $\mathrm{NO}_{3}{ }^{-}>\mathrm{SO}_{4}{ }^{2-}>\mathrm{Cl}^{-}>\mathrm{PO}_{4}{ }^{3-}$ para os ânions nas águas superficiais da bacia do Rio Jaú. Foram encontradas as maiores concentrações dos elementos $\mathrm{Ca}^{2+}$ e $\mathrm{Mg}^{2+}$ no ponto P5, antes da cidade de Jaú (Tabelas 1 e 2). Há aumento da concentração desses elementos na época de chuva, assim como ocorre para sólidos totais dissolvidos (STD), condutividade e $\mathrm{pH}$, provavelmente devido ao maior arraste de sedimentos por erosão laminar, aumentando, com isso, os valores obtidos de condutividade e $\mathrm{pH}$. Os constituintes $\mathrm{Na}^{+}$e $\mathrm{SiO}_{2}$, com maiores concentrações na época de seca, tiveram nos pontos $\mathrm{P} 6$ e $\mathrm{P} 2$, respectivamente, os maiores valores encontrados durante o período de coleta. Já o íon $\mathrm{K}^{+}$, com maior concentração no ponto $\mathrm{P} 3$, teve pequena variação entre o período seco e chuvoso.

Os valores obtidos para $\mathrm{Cl}^{-} \mathrm{e} \mathrm{SO}_{4}^{2-}$ são menores que o máximo permitido para águas de Classe 2 e Classe $3(250$ mg/L), segundo a Resolução CONAMA 357/05 (CONAMA, 2010). Contudo, os valores de $\mathrm{NO}_{3}{ }^{-}$apresentados nas Tabelas 1 e 2 indicam amostras acima do máximo permitido para a Classe 2 e Classe $3(10 \mathrm{mg} / \mathrm{L})$ como nos pontos P4 e P6. Quanto ao $\mathrm{PO}_{4}^{3-}$, com exceção de três amostras no ponto $\mathrm{P} 1$, todas as demais estão acima do máximo permitido para a Classe $2(0,1 \mathrm{mg} / \mathrm{L})$ e Classe $3(0,15 \mathrm{mg} / \mathrm{L})$ desta resolução. Os pontos P3 e P1 são os locais com maior e menor contribuição deste ânion para as águas fluviais da bacia do Rio Jaú, respectivamente. Os sólidos em suspensão provêm do carreamento de solos pelas águas pluviais, devido a processos erosivos e desmatamentos na bacia, do lançamento de esgotos domésticos, efluentes industriais, etc. (Hermes \& Silva, 2004). O aumento dos valores de sólidos totais dissolvidos (STD) na época chuvosa pode ser atribuído, provavelmente, ao maior arraste de sedimentos pela erosão laminar (solução lixiviada), que é mais acentuada neste período.

As correlações lineares de Pearson indicam que a composição química da água é influenciada por componentes geo e antropogênicos (Figura 5). Valores significativos envolvendo $\mathrm{Ca}^{2+}$ e $\mathrm{Mg}^{2+}$ foram encontrados no Ribeirão do Bugio $(\mathrm{P} 1=0,99$ - Figura 5a) e $(\mathrm{P} 2=0,83)$, Ribeirão São João (P3 = 0,96 e P4 = 0,95) e Rio Jaú (P5 = 0,99 e P6 = 0,99), cuja provável entrada se deve a poeiras de solos agrícolas. Correlações entre $\mathrm{Na}^{+} \mathrm{e} \mathrm{K}$ foram encontradas no Ribeirão do Bugio $(\mathrm{P} 1=0,91)$ e $(\mathrm{P} 2=0,94-$ Figura $5 \mathrm{~b})$, provavelmente relacionadas com poeiras de solos derivados de silicatos,

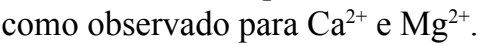
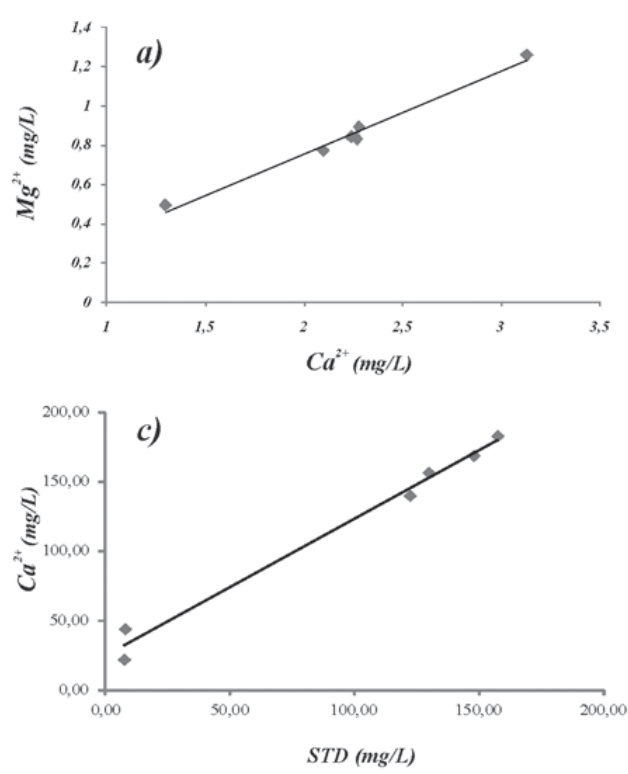
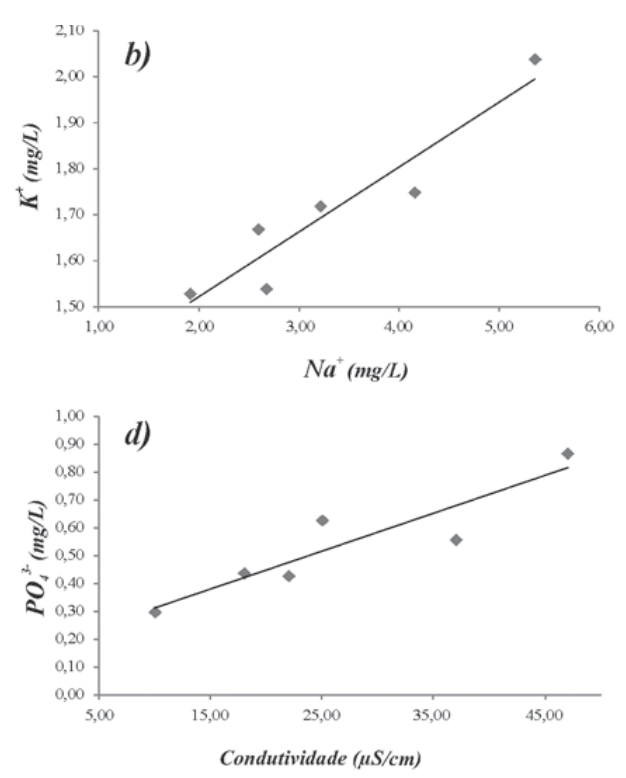

Figura 5 - Correlações (P $\leq 0,01)$ entre os parâmetros obtidos nas águas superficiais da bacia do Rio Jaú. (a) cálcio e magnésio no ponto P1. (b) sódio e potássio no ponto $P 2$. (c) sólidos totais dissolvidos e cálcio no ponto P5. (d) condutividade e fosfato no ponto P3. 
Correlações indicando a entrada de poeiras de solos derivados de silicatos também foram observadas entre STD e $\mathrm{Ca}^{2+}$ no Ribeirão do Bugio (P1 = 0,90) e Rio Jaú (P5 = 0,99 - Figura 5c) e $(\mathrm{P} 6=0,99)$ e entre STD e $\mathrm{Mg}^{2+}$ no Ribeirão do Bugio $(\mathrm{P} 1=0,89)$, Ribeirão São João $(\mathrm{P} 3=0,67)$ e Rio Jaú (P5 = 0,99 e P6 = 0,96). Correlações no Ribeirão do Bugio entre STD e $\mathrm{NO}_{3}^{-}(\mathrm{P} 1=0,88$ e P2 = 0,72) e no Ribeirão São João entre condutividade e $\mathrm{PO}_{4}{ }^{3-}(\mathrm{P} 3=0,91$ - Figura $5 \mathrm{~d})$ também foram observadas, cuja provável origem estaria relacionada com o carreamento de fertilizantes fosfatados ou resíduos da queima de biomassa e/ou combustíveis fósseis.

\section{Fluxo anual de cátions e ânions e denudação química}

O valor do fluxo anual de cátions e ânions ( $\left.\mathrm{t} / \mathrm{km}^{2} / \mathrm{ano}\right)$ em uma bacia hidrográfica está relacionado com a média ponderada de cátions e ânions, assim como à área e à vazão média de cada ponto de amostragem (Moreira-Nordemann, 1980, 1984). Quando estes valores e as concentrações médias ponderadas (Tabela 2) são utilizados, então, é possível estimar as taxas representadas na Tabela 3 e ilustradas na Figura 6.

Tabela 3 - Valores do fluxo anual (t/km²/ano) para os principais cátions e ânions da bacia do Rio Jaú.

\begin{tabular}{ccccccccccccccccc}
\hline Ponto & $\begin{array}{c}\mathbf{Q} \text { média } \\
\left(\mathbf{m}^{3} / \mathbf{s}\right)\end{array}$ & $\begin{array}{c}\text { Área } \\
\left(\mathbf{k m}^{2}\right)\end{array}$ & $\mathbf{C a}^{2+}$ & $\mathbf{M g}^{2+}$ & $\mathbf{N a}^{+}$ & $\mathbf{K}^{+}$ & $\mathbf{S i O}_{2}$ & $\mathbf{C l}^{-}$ & $\mathbf{P O}_{4}{ }^{3-}$ & $\mathbf{S O}_{4}{ }^{2-}$ & $\mathbf{N O}_{3}^{-}$ \\
\hline P1 & 0,13 & 6,72 & 1,32 & 0,50 & 0,43 & 0,57 & 1,48 & 0,14 & 0,13 & 2,07 & 1,84 \\
P2 & 3,56 & 185,01 & 4,53 & 1,83 & 1,90 & 1,02 & 9,22 & 0,54 & 0,29 & 1,33 & 2,56 \\
P3 & 0,13 & 6,98 & 3,78 & 1,20 & 0,81 & 2,18 & 4,13 & 1,04 & 0,31 & 2,03 & 1,17 \\
P4 & 1,21 & 63,04 & 3,93 & 1,60 & 1,71 & 0,97 & 2,97 & 0,67 & 0,29 & 1,75 & 3,16 \\
P5 & 6,84 & 355,18 & 63,72 & 3,70 & 1,95 & 1,02 & 0,81 & 1,38 & 0,25 & 2,13 & 2,95 \\
P6 & 9,00 & 467,16 & 18,36 & 2,87 & 2,82 & 1,22 & 8,39 & 1,13 & 0,25 & 2,51 & 4,09 \\
\hline
\end{tabular}

Os parâmetros cálcio, magnésio e nitrato possuem um comportamento semelhante, ou seja, aumentam de montante (P1 e P3) para jusante (P2 e P4). Com exceção do sulfato, a mesma dinâmica ocorre no Ribeirão do Bugio para todos os outros parâmetros $\left(\mathrm{K}^{+}, \mathrm{SiO}_{2}, \mathrm{Cl}^{-}, \mathrm{PO}_{4}^{3-}\right)$. Fato inverso ocorre no Ribeirão São João, isto é, maior concentração a montante e menor a jusante. No Rio Jaú (P5 e P6), com exceção de $\mathrm{Ca}^{2+}$, $\mathrm{Mg}^{2+}$ e $\mathrm{Cl}^{-}$todos os outros parâmetros analisados possuem uma concentração maior no ponto (P6), próximo à foz com o Rio Tietê. No entanto, a soma total de cátions e ânions ( $\mathrm{t}$ / $\mathrm{km}^{2} / \mathrm{ano}$ ) é maior no ponto (P5), devido à alta concentração

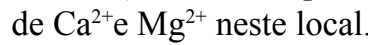

Os valores obtidos para os pontos P1 e P3 próximos às duas nascentes do Ribeirão do Bugio e Ribeirão São João, formadores do Rio Jaú, são representativos de características próximas ao comportamento natural de cátions e ânions dissolvidos nas águas da bacia do Rio Jaú. Relativamente a estes dois pontos, no geral, os maiores valores do fluxo anual foram obtidos no Ribeirão São João (P3), que flui principalmente sobre o arenito da Formação Itaqueri, composto por quartzo $=\mathrm{SiO}_{2}$, feldspato potássico $=\mathrm{KAlSiO}_{3} \mathrm{O}_{8}$, albita $=(\mathrm{NaCa})(\mathrm{SiAl})_{4} \mathrm{O}_{8} \mathrm{e}$ caulinita $=\mathrm{Al}_{2} \mathrm{Si}_{2} \mathrm{O}_{5}(\mathrm{OH})_{4}$. Relativamente a $\mathrm{P} 3$, com exceção de sulfato, os menores valores do fluxo anual foram obtidos no Ribeirão do Bugio (P1), que também recebe a contribuição da alteração do arenito da Formação Ita- queri, de mesma composição mineralógica. Os pontos P2 (Ribeirão do Bugio) e P4 (Ribeirão São João) localizados a jusante dos municípios de Dois Córregos e Mineiros do Tietê, respectivamente, recebem a contribuição do intemperismo dos basaltos da Formação Serra Geral, nos quais feldspato potássico $=\mathrm{KAlSiO}_{3} \mathrm{O}_{8}$, anortoclásio = $\mathrm{Na}_{0,71} \mathrm{~K}_{0,29} \mathrm{AlSiO}_{3} \mathrm{O}_{8}$, augita $=\mathrm{Ca}(\mathrm{Fe}, \mathrm{Mg}) \mathrm{Si}_{2} \mathrm{O}_{6}$, esmectita $=\mathrm{Al}_{2} \mathrm{O}_{3}, \mathrm{SiO}_{2} \mathrm{H}_{2} \mathrm{O} \cdot \mathrm{H}_{2} \mathrm{O}$ e caulinita $=\mathrm{Al}_{2} \mathrm{Si}_{2} \mathrm{O}_{5}(\mathrm{OH})_{4}$ fazem parte da composição mineralógica. Aparentemente com a mesma composição mineralógica, os pontos P5 e P6 (Rio Jaú), também recebem a contribuição da alteração dos basaltos da Formação Serra Geral.

As rochas da bacia do Rio Jaú não possuem mi-

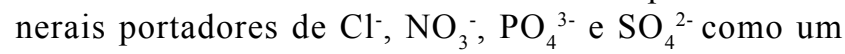
constituinte principal (Figura 4), consequentemente, pouca entrada natural desses elementos/compostos é esperada nas águas devido aos processos de interação água/rocha. Assim, o fluxo anual de $\mathrm{Cl}^{-}, \mathrm{NO}_{3}{ }^{-}, \mathrm{PO}_{4}{ }^{3-} \mathrm{e}$ $\mathrm{SO}_{4}{ }^{2-}$ nos pontos $\mathrm{P} 1$ e $\mathrm{P} 3$ poderia, em princípio, ser atribuído às entradas antropogênicas como, pastagens e atividades agrícolas (Figura 2). Isto porque, no geral, os resultados indicam um aumento de seus valores ao longo dos afluentes do Rio Jaú. Por exemplo, para o $\mathrm{Cl}^{-}$, o valor em P1 é de $0,14 \mathrm{t} / \mathrm{km}^{2} /$ ano, enquanto que em P2 corresponde a $0,54 \mathrm{t} / \mathrm{km}^{2} / \mathrm{ano}$. 

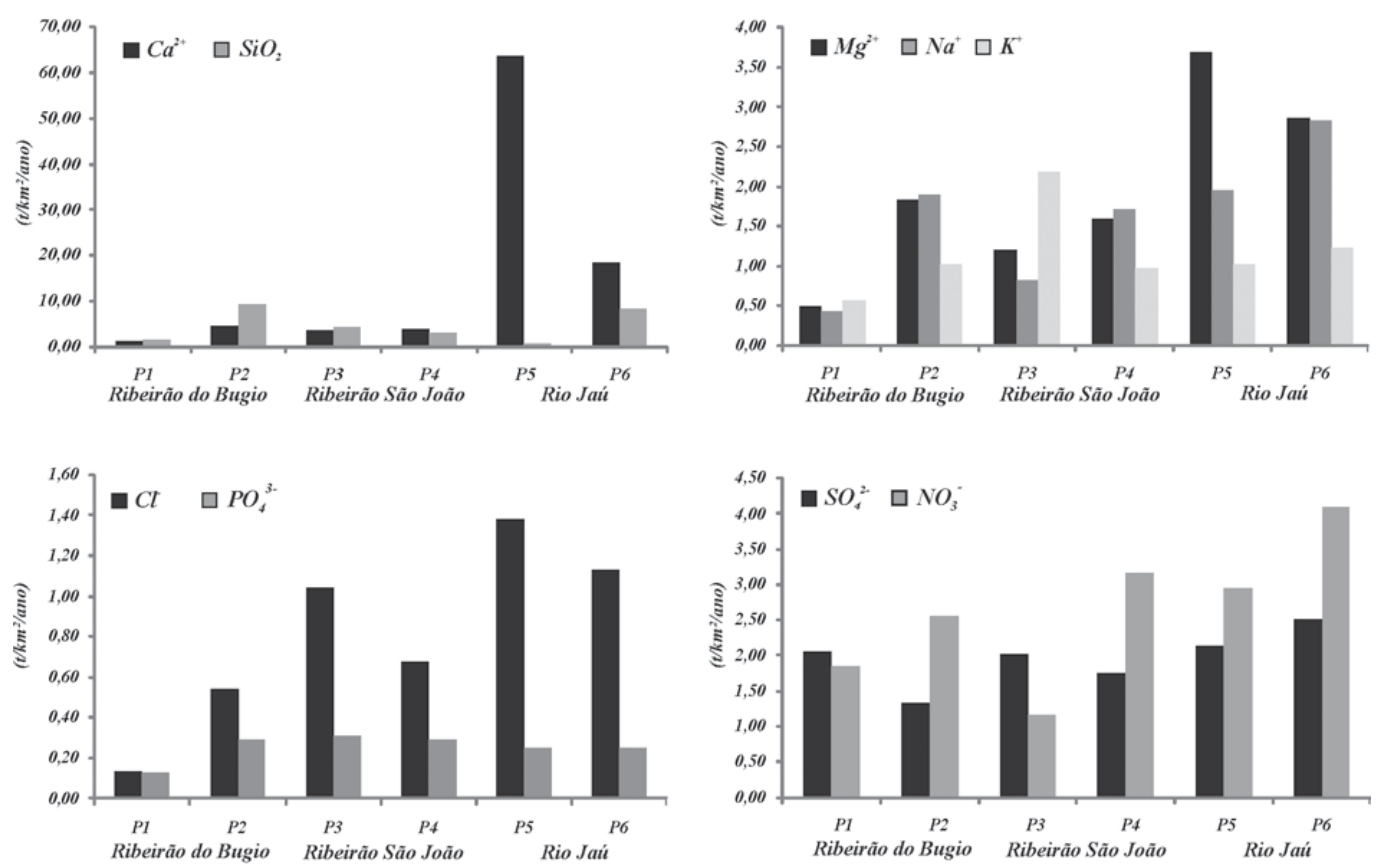

Figura 6 - Transporte especifico ( $\left(t / \mathrm{km}^{2} / a n o\right)$ de cátions e ânions na bacia do Rio Jaú. P1 e P2 = Ribeirão do Bugio, P3 e P4 = Ribeirão São João, P5 e P6 = Rio Jaú.

O substrato geológico disponibiliza materiais que compõem os sólidos totais dissolvidos (STD) nas águas fluviais. Assim, a denudação química pode ser entendida como a perda de material do substrato rochoso de uma bacia hidrográfica, que envolve a remoção de material dissolvido, tendo como agente de transporte à água. Como a bacia não

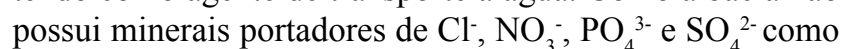
um constituinte principal (Figura 4), o fluxo anual de STD foi calculado com base na concentração de $\mathrm{Ca}^{2+}+\mathrm{Mg}^{2+}+$ $\mathrm{Na}^{+}+\mathrm{K}^{+}+\mathrm{SiO}_{2}$ (Tabela 4), solubilizados pela hidrólise dos minerais que ocorrem na bacia:

$$
\begin{aligned}
& 2 \mathrm{KAlSi}_{3} \mathrm{O}_{8}+2 \mathrm{CO}_{2}+4 \mathrm{H}_{2} \mathrm{O} \rightarrow \mathrm{Al}_{2} \mathrm{Si}_{4} \mathrm{O}_{10}(\mathrm{OH})_{2}+2 \mathrm{~K}^{+} \\
& +2 \mathrm{HCO}_{3}^{-}+2 \mathrm{SiO}_{2} \\
& 2 \mathrm{NaAlSi}_{3} \mathrm{O}_{8}+2 \mathrm{CO}_{2}+3 \mathrm{H}_{2} \mathrm{O} \rightarrow \mathrm{Al}_{2} \mathrm{Si}_{2} \mathrm{O}_{5}(\mathrm{OH})_{4}+2 \mathrm{Na}^{+} \\
& +2 \mathrm{HCO}_{3}^{-}+4 \mathrm{SiO}_{2} \\
& 2 \mathrm{NaAlSi}_{3} \mathrm{O}_{8}+2 \mathrm{CO}_{2}+4 \mathrm{H}_{2} \mathrm{O} \rightarrow \mathrm{Al}_{2} \mathrm{Si}_{4} \mathrm{O}_{10}(\mathrm{OH})_{2}+2 \mathrm{Na}^{+} \\
& +2 \mathrm{HCO}_{3}^{-}+2 \mathrm{SiO}_{2} \\
& \mathrm{CaAl}_{2} \mathrm{Si}_{2} \mathrm{O}_{8}+2 \mathrm{CO}_{2}+2 \mathrm{H}_{2} \mathrm{O} \rightarrow \mathrm{Al}_{2} \mathrm{Si}_{2} \mathrm{O}_{5}(\mathrm{OH})_{4}+\mathrm{Ca}^{2+} \\
& +2 \mathrm{HCO}_{3}^{-} \\
& 2 \mathrm{CaMgAl}_{2} \mathrm{SiO}_{12}+2 \mathrm{CO}_{2}+2 \mathrm{H}_{2} \mathrm{O} \rightarrow \mathrm{Al}_{4} \mathrm{Si}_{2} \mathrm{O}_{10}(\mathrm{OH})_{14}+ \\
& 2 \mathrm{Ca}^{2+}+2 \mathrm{Mg}^{2+}+2 \mathrm{HCO}_{3}^{-} \\
& \mathrm{NaKAlSi}_{3} \mathrm{O}_{8}+2 \mathrm{CO}_{2}+2 \mathrm{H}_{2} \mathrm{O} \rightarrow \mathrm{AlSi}_{3} \mathrm{O}_{6}(\mathrm{OH})_{2}+ \\
& 2 \mathrm{HCO}_{3}^{-}+\mathrm{Na}^{+}+\mathrm{K}^{+}
\end{aligned}
$$

\begin{tabular}{|c|c|c|c|c|}
\hline Ponto & Geologia & Relevo & $\begin{array}{c}\text { Altitude } \\
\text { (m) }\end{array}$ & $\begin{array}{c}{ }^{1} S T D \\
\text { t/km²/ano }\end{array}$ \\
\hline P1 & Fm Itaquerí & Colinas médias & 750,5 & 4,291 \\
\hline $\mathbf{P 2}$ & Fm Serra Geral & Morrotes alongados e espigões & 558,5 & 18,508 \\
\hline P3 & Fm Itaquerí & Colinas médias & 678,0 & 12,101 \\
\hline P4 & Fm Serra Geral & Morrotes alongados e espigões & 582,5 & 11,185 \\
\hline P5 & Fm Serra Geral & Morrotes alongados e espigões e colinas amplas & 495,5 & 71,200 \\
\hline P6 & Fm Serra Geral & Morrotes alongados e espigões e colinas amplas & 457,0 & 33,665 \\
\hline
\end{tabular}

Tabela 4 - Taxa de denudação química (t/ $\left.\mathrm{km}^{2} / \mathrm{ano}\right)$ na bacia do Rio Jaú.

${ }^{1} \mathrm{STD}=$ Sólidos Totais Dissolvidos com base nos constituintes $\mathrm{Ca}^{2+}+\mathrm{Mg}^{2+}+\mathrm{Na}^{+}+\mathrm{K}^{+}+\mathrm{SiO}_{2}$. 
Os fluxos de sólidos totais dissolvidos de 4,29 e 12,10 $\mathrm{t} / \mathrm{km}^{2} /$ ano para $\mathrm{P} 1$ e $\mathrm{P} 3$, respectivamente, demonstram que um mesmo litotipo e unidade de relevo podem apresentar um comportamento denudacional diferente (Tabela 4). Para os pontos $\mathrm{P} 2$ e $\mathrm{P} 4$, os vales fechados possuem drenagem de média $\left(\mathrm{P} 4=11,18 \mathrm{t} / \mathrm{km}^{2} / \mathrm{ano}\right)$ a alta densidade $(\mathrm{P} 2=18,50 \mathrm{t} /$ $\mathrm{km}^{2}$ /ano), fatos observados nos valores transportados pelas drenagens analisadas. Já os fluxos de sólidos totais dissolvidos (STD) nos pontos P5 e P6 foram de 71,20 t/ $\mathrm{km}^{2} /$ ano e 33,66 t/ $\mathrm{km}^{2} /$ ano respectivamente, demonstrando um comportamento denudacional diferente, apesar do mesmo substrato geológico e unidade de relevo. A vazão do canal fluvial (P5 = 6,84 m³ $/ \mathrm{s}$ e P6 $=9,0 \mathrm{~m}^{3} / \mathrm{s}$ ) pode interferir na intensidade da denudação química, conforme verificado por Salgado et al. (2004) e Salgado \& Valadão (2005). Parte dos íons analisados podem ser diluídos, retidos pela biota ou solos, não alcançando o exutório da bacia, onde um mesmo litotipo em uma mesma região, pode apresentar um comportamento denudacional de intensidade variável.

Neste contexto, pode-se considerar que, parte da origem de cátions e ânions nas águas superficiais da bacia do Rio Jaú é devido ao intemperismo das rochas sedimentares e ígneas das Formações Itaqueri e Serra Geral, segundo a reação: minerais primários $+\mathrm{H}_{2} \mathrm{O}+\mathrm{CO}_{2} \rightarrow$ minerais secundários (argilas) $+\mathrm{HCO}_{3}{ }^{-}+$solução lixiviada $\left(\mathrm{Ca}^{2+}\right.$, $\mathrm{Mg}^{2+}, \mathrm{Na}^{+}, \mathrm{K}^{+}$e $\mathrm{SiO}_{2}$ ). Isto implica dizer que, considerando os elementos lixiviados pelos principais minerais formadores das rochas $\left(\mathrm{t} / \mathrm{km}^{2} / \mathrm{ano}\right)$ e a área de influência $\left(\mathrm{km}^{2}\right)$, o Ribeirão do Bugio (P2), remove e transporta 3.424,14 toneladas de material por ano ao Rio Jaú. Já o Ribeirão São João (P4), remove e transporta 705,09 toneladas de material por ano ao Rio Jaú. Por fim, o exutório da bacia na bacia do Rio Jaú (P6), remove e transporta o equivalente a $15.727,15$ toneladas de material por ano ao Rio Tietê (Tabela 5).

Tabela 5 - Quantidade de material removido (t/ano) nas sub-bacias e na bacia do Rio Jaú.

\begin{tabular}{lcc}
\hline \multicolumn{1}{c}{ Ponto } & $\begin{array}{c}\text { Área da } \\
\text { bacia }\left(\mathbf{k m}^{2}\right)\end{array}$ & $\begin{array}{c}\text { Material removido } \\
\text { (t/ano) }\end{array}$ \\
\hline P2 - Ribeirão do Bugio & 185,01 & $3.424,14$ \\
P4 - Ribeirão São João & 63,04 & 705,09 \\
P6 - Rio Jaú* & 467,16 & $15.727,15$ \\
\hline
\end{tabular}

${ }^{*}$ Exutório da bacia do Rio Jaú

\section{Considerações finais}

O presente trabalho investigou a denudação química e as implicações na composição das águas superficiais da bacia do Rio Jaú (SP). Os valores obtidos para os principais cátions e ânions indicaram a seguinte tendência $\mathrm{Ca}^{2+}>\mathrm{SiO}_{2}>\mathrm{NO}_{3}{ }^{-}>\mathrm{SO}_{4}{ }^{2-}>\mathrm{Mg}^{2+}>\mathrm{Na}^{+}>\mathrm{K}^{+}>\mathrm{Cl}^{-}>$ $\mathrm{PO}_{4}^{3-}$ encontrada para as águas superficiais da bacia do Rio Jaú. As rochas da bacia do Rio Jaú não possuem minerais portadores de $\mathrm{Cl}^{-}, \mathrm{NO}_{3}{ }^{-}, \mathrm{PO}_{4}{ }^{3-}$ e $\mathrm{SO}_{4}{ }^{2-}$ como um constituinte principal, e, consequentemente, pouca entrada natural desses elementos/compostos é devido aos processos de interação água/rocha. Assim, a denudação química (t/ano) na bacia do Rio Jaú foi calculada com base na concentração de $\mathrm{Ca}^{2+}, \mathrm{Mg}^{2+}, \mathrm{Na}^{+}, \mathrm{K}^{+}$e $\mathrm{SiO}_{2}$ (solução lixiviada dos minerais que compõem as rochas da bacia). Os resultados indicaram que os pontos P1 e P3, nascentes dos Ribeirões do Bugio e São João que drenam áreas onde afloram as rochas da Formação Itaqueri (Colinas Médias), apresentam uma denudação anual de 28,84 e 84,46 toneladas. Estes valores são bem diferentes daqueles nos pontos P2 (3424,14 t/ano) e P4 (705,08 t/ ano) localizados a montante, que drenam as rochas ígneas da Formação Serra Geral (Morrotes Alongados e Espigões). A denudação química no Rio Jaú (pontos P5 e P6) demonstrou um comportamento diferente, apesar do mesmo substrato geológico e unidade de relevo.

Considerando as duas sub-bacias formadoras do Rio Jaú (Ribeirão do Bugio e Ribeirão São João), chegou-se a total de 4.129,23 toneladas de material transportado e removido por ano, ou seja, aproximadamente $26,25 \%$ de contribuição. No ponto P6, exutório da bacia, antes da confluência com o Rio Tietê, chegou-se ao equivalente de $15.727,15$ toneladas de material transportado e removido. Os resultados da presente investigação possibilitam compreender a influência do substrato geológico/geomorfológico na quantidade/qualidade de material dissolvido removido pelas drenagens da bacia do Rio Jaú. As rochas sedimentares da Formação Itaquerí estão localizadas em relevos de alta declividade, onde a ação do escoamento superficial sobrepõe-se à infiltração levando a formação de solos rasos, consequentemente, menor tempo de contato e/ou interação água/rocha, menor quantidade de material sendo removido. Já as rochas ígneas da Formação Serra Geral, localizadas em relevos de colinas e planícies, com tendência à infiltração da água, favorece o desenvolvimento de solos mais profundos devido ao maior tempo de contato e/ou interação água/ rocha, consequentemente, maior quantidade de material sendo removido.

\section{Agradecimentos}

Os autores agradecem ao CNPq (Processo $n^{\circ}$ 142756/2008-3) pelo apoio concedido durante a realização deste trabalho. Além disso, os autores também agradecem aos relatores anônimos pelos comentários e sugestões que nos ajudaram a melhorar este manuscrito. 


\section{Referências bibliográficas}

Companhia de Tecnologia de Saneamento Ambiental. CETESB. Decreto $\mathrm{n}^{\circ} 8.468$, de 8 de setembro de 1976. Aprova o regulamento da Lei ${ }^{\circ}$ 997, de 31 de maio de 1976, que dispõe sobre a Prevenção e Controle da Poluição do Meio Ambiente. Disponível em http:// www.cetesb.sp.gov.br/Institucional/portugues_leis_dec.asp. Acesso em 26/10/2010.

Companhia de Tecnologia de Saneamento Ambiental. CETESB. Decreto $\mathrm{n}^{\circ} 10.755$, de 22 de novembro de 1977. Dispõe sobre o enquadramento dos corpos de água receptores na classificação prevista no Decreto ${ }^{\circ} 8.468$, de 8 de setembro de1976, e dá providências correlatas. Disponível em http://licenciamento.cetesb. sp.gov.br/legislacao/estadual/decretos/decretos.asp. Acesso em 05/07/2012.

Conceição F.T.; Sardinha D.S.; Souza A.D.G.; Bonotto, D.M. Hydrochemical Relationships at Meio Stream Watershed, São Paulo State, Brazil. Revista Brasileira de Geociências, 2007, vol. 37, pp. 389-400.

Conceição F.T.; Santos C.M.; Souza A.D.G.; Lima V.B.; Sardinha D.S.; Navarro G.R.B. Avaliação do transporte específico de cátions e ânions na bacia do Ribeirão Preto (SP). Geochimica Brasiliensis, 2012, no prelo.

Conselho Nacional do Meio Ambiente. CONAMA. Resolução ${ }^{\circ}$ 357, de 17 de março de 2005. Disponível em http://www.mma.gov. br/port/conama/legiano. Acesso em 26/10/2010.

Hach. Water Analysis Handbook. Hach Company, Loveland, Colorado, USA, $2^{\circ}$ edição, 1992, 831p.

Hermes L.C.; Silva A. de S. Avaliação da qualidade das águas: manual prático. Brasília: Embrapa Informação Tecnológica, 2004, 55p.

Instituto Brasileiro de Geografia e Estatística. IBGE. Carta Brasil 1:50.000 folha SF-22-Z-B-III-3 Dois Córregos. Superintendência em Cartografia, 1973a.

Instituto Brasileiro de Geografia e Estatística. IBGE. Carta Brasil 1:50.000 folha SF-22-Z-B-II-4 Jaú. Superintendência em Cartografia, 1973b.

Instituto de Pesquisas Tecnológicas do Estado de São Paulo. IPT. Mapa Geomorfológico do Estado de São Paulo. Escala 1:1.000.000. São Paulo: IPT, Vol 2, 1981, série monografias, 5, 180p.

Instituto de Pesquisas Tecnológicas do Estado de São Paulo. IPT. Comitê da Bacia Hidrográfica do Tietê Jacaré-CBH-TJ. Relatório, 40.674. São Paulo: 2006, FEHIDRO, IPT, 331p.

Moreira-Nordemann L.M. Use of ${ }^{234} \mathrm{U} /{ }^{238} \mathrm{U}$ disequilibrium in measuring chemical weathering rate of rocks. Geochimica et Cosmochimica Acta, 1980, vol. 44, pp. 103-108.

Moreira-Nordemann L.M. Salinity and weathering rate of rocks in a semi-arid region. Journal of Hydrology, 1984, vol. 71, pp. 131-147.

Mortatti J.; Victoria R.L.; Tardy Y. Balanço de alteração e erosão química na Bacia Amazônica. Geochimica Brasiliensis, 1997, vol. 11, n. 1, pp. 1-13.
Mortatti J.; Probst J.L; Fernandes A. M.; Mortatti B.C.; Oliveira, $\mathrm{H}$. Influence of discharge on silicate weathering of the Tietê river basin: major cations and dissolved silica approach. Geochimica Brasiliensis, 2008, vol. 22, pp. 15-26.

Rezende J.H. Análise Fluviológica e Ambiental da Bacia Hidrográfica do Rio Jaú - SP. Tese - Universidade Federal de São Carlos, Centro de Ciências Biológicas e da Saúde. São Carlos, 2009, 152p.

Riccomini C. Considerações sobre a posição estratigráfica e tectonismo deformador da Formação Itaquerí na porção centro leste do estado de São Paulo. Revista do Instituto de Geociências, 1997, Vol. 18, pp. 41-48.

Salgado A.A.R.; Valadão R.C. Contribuição da Desnudação Geoquímica na Evolução da Erosão Diferencial no Espinhaço Meridional - MG. Revista Brasileira de Geomorfologia, Ano 4, $\mathrm{n}^{\circ}$ 2, 2003, pp. 31-40.

Salgado A.A.R.; Colin F.F.; Nalini H.A. Jr.; Braucher R.; Varajão A.F.; Varajão C.A.C. O papel da denudação geoquímica no processo de erosão diferencial no Quadrilátero Ferrífero/MG. Revista Brasileira de Geomorfologia, Ano 5, $\mathrm{n}^{\circ}$ 1, 2004, pp. 55-69.

Salgado A.A.R.; Valadão R.C. Fatores controladores dos processos desnudacionais geoquímicos no Espinhaço Meridional (Depressão de Gouveia, MG). Revista Geonomos, vol. 13, 2005, pp. 51-57.

Sardinha D.S.; Conceição F.T.; Bonotto D.M.; Salles M.H.D.; Angelucci V.A. Avaliação de balanço anual de cátions e ânions na bacia do Alto Sorocaba (SP). Revista Brasileira de Geociências, 2008, vol, 38, pp. 730-740.

Sardinha D.S.; Bonotto D.M. Conceição F.T. Weathering rates at Alto Sorocaba basin, Brazil, using U-isotopes and major cations. Environmental Earth Sciences, 2010, Vol. 61, pp. 1025-1036.

Sardinha D.S. Avaliação da taxa de intemperismo químico na bacia do Rio Jaú (SP). Tese apresentada ao Instituto de Geociências e Ciências Exatas para obtenção do título de doutor em Geologia Regional. UNESP, Rio Claro, 2011, 109p.

Sistema Integrado de Gerenciamento de Recursos Hídricos de São Paulo. SIGRH. Banco de dados pluviométrico e fluviométricos do estado de São Paulo. Disponível em www.sigrh.sp.gov.br. Acesso em 24/07/2009.

Squisato E.; Nardy A.J.R.; Machado F.B.; Marques L.S.; Rocha JR E.R.V.; Oliveira M.A.F. Litogeoquímica e aspectos petrogenéticos dos basaltos da província magmática do Paraná na porção centronorte do estado de São Paulo. São Paulo, UNESP, Geociências, 2009, v. 28, n. 1, pp. 27-41.

Suguio K. Geologia sedimentar. São Paulo: Edgard Blucher, $1^{\circ}$ edição, 2003, 400p.

Teixeira W.; ToledoM.C.M.; Fairchild T.R.; Taioli F. Decifrando a Terra. São Paulo: Oficina de textos, $1^{\circ}$ edição, 2000, 568p.

Tucci C.E.M. Hidrologia. Porto Alegre: Editora da Universidade Federal do Rio Grande do Sul, 2001, pp. 443-484. 